\title{
Emotional Well-Being Under Conditions of Lockdown: An Experience Sampling Study in Austria During the COVID-19 Pandemic
}

\author{
Stefan Stieger ${ }^{1}$ (D) David Lewetz ${ }^{1} \cdot$ Viren Swami $^{2,3}$
}

Accepted: 24 November 2020 / Published online: 2 January 2021

(c) Springer Nature B.V. 2021

\begin{abstract}
The coronavirus (COVID-19) pandemic and attendant lockdown measures present serious threats to emotional well-being worldwide. Here, we examined the extent to which being outdoors (vs. indoors), the experience of loneliness, and screen-time are associated with emotional well-being during the COVID-19 pandemic using an experiencing sampling method. In April 2020, Austrian adults $(N=286$, age $M=31.0$ years) completed a 21-day experience sampling phase in which they reported their emotional well-being (i.e., happiness), whether they were indoors or outdoors, and loneliness at three random timepoints each day, as well as their daily screen-time. Results indicated that being outdoors was associated with higher emotional well-being, whereas greater loneliness and greater daily screen-time were associated with poorer well-being. Additionally, the impact of loneliness on well-being was weaker when participants were outdoors than indoors. These results have health policy implications for the promotion of population well-being during pandemics.
\end{abstract}

Keywords Coronavirus · COVID-19 · Emotional well-being · Outdoors · Loneliness · Screen-time

\section{Introduction}

The coronavirus (COVID-19) pandemic presents a serious threat to physical and mental health worldwide. In Austria, where the present study was conducted, 16,300 individuals had tested positive for COVID-19 and 630 had died as of 20th of May, 2020 (Ministry of Social Affairs 2020). To limit the spread of the coronavirus, the Austrian government

Stefan Stieger and Viren Swami contributed equally

Stefan Stieger

stefan.stieger@kl.ac.at

1 Department of Psychology and Psychodynamics, Karl Landsteiner University of Health Sciences,

Dr.-Karl-Dorrek-Straße 30, 3500 Krems an der Donau, Austria

2 School of Psychology and Sport Science, Anglia Ruskin University, Cambridge, UK

3 Centre for Psychological Medicine, Perdana University, Serdang, Malaysia 
announced a nationwide restriction on outdoor activities on March 16, with individuals only allowed to leave the home under specific conditions. While these prevention measures can be effective against disease transmission [e.g. (Tian et al. 2020)], the impact of lockdowns - and the resulting changes in behaviour patterns and functioning-on emotional well-being is likely to be substantive (Fiorilo and Gorwood 2020; Galea et al. 2020; Swami et al. 2021; Torales et al. 2020). Indeed, emerging evidence from other nations indicates that lockdown measures have led to increases in depressive symptoms, anxiety, and severe stress [e.g., (Gao et al. 2020; Newby et al. 2020; Qiu et al. 2020; Tull et al. 2020; Wang et al. 2020); for a review, see (Brooks et al. 2020)], which is consistent with the findings of earlier studies on the psychological consequences of other pandemics [e.g., (Hawryluck et al. 2004; Wheaton et al. 2012)].

Against this background, understanding the factors that may shape daily emotional wellbeing is vital, not only for nations that continue to enforce lockdown measures, but also for minimising adverse effects on well-being during possible future pandemics. One of the most important factors that is likely to have an impact on emotional well-being under conditions of lockdown is the ability to go outdoors. Under normal circumstances, there is a wealth of evidence showing that being outdoors is associated with wide-ranging positive outcomes in terms of emotional well-being [for reviews, see (Bowler et al. 2010; Collado et al. 2017; Frumkin et al. 2017; Hartig et al. 2014; Kondo et al. 2018; Bosch and Bird 2018)]. Under conditions of social distancing, where outdoor recreation is severely reduced and restricted [(Rice et al. 2020); for Austrian data, see (Google 2020)], the ability to spend time outdoors is likely to take on added importance vis-à-vis emotional wellbeing (Burtscher et al. 2020). Indeed, there is some evidence from Europe that the public are more aware of the importance of spending time in natural environments during the COVID-19 pandemic (Rousseau and Deschacht 2020) and that being outdoors was associated with significantly higher positive affect and lower negative feelings (Lades et al. 2020).

Another important consideration under conditions of physical and social distancing that may impact emotional well-being is the experience of loneliness (Banerjee and Rai 2020; Tull et al. 2020), which can be defined as the negative emotional state that derives from a subjective perception of deficiencies in one's social relationships (Russell et al. 1984). That is, under conditions of social distancing, individuals are likely to reduce the number of others with whom they have regular contact both physically (i.e., physical separation from others) and socially (i.e., limited social interaction with others), which heightens feelings of loneliness (2020). In turn, loneliness is a known risk factor for poorer emotional well-being [e.g., (Cuenya et al. 2012; Wilson et al. 2007)], particularly when periods of isolation are prolonged (Stickley and Koyanagi 2016). Indeed, emerging evidence suggests that greater loneliness was significantly associated with greater anxiety and depressive symptoms during the COVID-19 pandemic (2020; Losada-Baltar et al. 2020; Okruszek et al. 2020; Palgi et al. 2020). However, the impact of physical and social distancing on loneliness is likely to be complicated by age: while older adults have been identified as being particularly at risk for loneliness under conditions of social distancing (Berg-Weger and Morley 2020; Patel and Clark-Ginsberg 2020), the evidence from Spain and the United States indicates that it was in fact younger respondents who reported greater loneliness (Losada-Baltar et al. 2020; Luchetti et al. 2020).

A final factor worthy of consideration is screen-time: the evidence from China (Xiang et al. 2020) and Italy (Pietrobelli et al. 2020), for example, indicates that sedentary screentime increased by about $30 \mathrm{~h}$ per week during the COVID-19 pandemic. This is important because increased screen-time may interfere with face-to-face social interactions and 
thereby increase feelings of loneliness, with upstream negative impacts on emotional wellbeing [for a meta-analysis, see (Huang 2017)]. It is also possible that increased screentime interferes with outdoor recreation (Wen et al. 2009), which in turn limits opportunities for promoting well-being. However, outside conditions of social distancing, studies examining associations between screen-time and emotional well-being have been equivocal at best, with some studies reporting that increased screen-time is associated with poorer well-being, others reporting small, positive effects on mental health (particularly when used to facilitate direct social interactions with peers), and yet others reporting no significant associations [for a review, see (Odgers and Jensen 2020)]. However, much of the evidence base is limited to adolescents and children and there is little research on the impact of screen-time on emotional well-being under conditions of lockdown (Hamilton et al. 2020), particularly as patterns of screen usage may be more variable during this period (e.g., screen-time may also facilitate social interactions with others). Preliminary evidence suggests equivocal relationships between screen-time and emotional well-being: data from China suggests that screen-time was not significantly associated with positive or negative affect (Qin et al. 2020), whereas data from Canada indicates that increased screen-time was associated with poorer self-rated mental health (Colley et al. 2020). It is also possible that increased screen-time under conditions of social distancing will be associated with lower levels of loneliness (Pancani et al. 2020).

While the review above suggests that there are likely to be several major factors influencing emotional well-being under conditions of social distancing, a number of limitations of existing research are noteworthy. First, previous studies have tended to examine the aforementioned factors in isolation, which precludes the possibility of considering and examining interactionist effects. Second, many previous studies-and especially studies on the impact of the COVID-19 pandemic - have typically utilised cross-sectional data. This is important because cross-sectional research relies on retrospective assessments that may be subject to recall biases and because it is unable to provide moment-to-moment assessments of psychological well-being (Ellison et al. 2020). In contrast, the experience sampling method (ESM; also referred to as ecological momentary assessment or ambulatory assessment) affords an ideal research tool for examining such effects as they occur in individuals' everyday lives (Bolger and Laurenceau 2013; Mehl and Conner 2012). In ESM research, respondents are asked to complete brief surveys on multiple, semi-random occasions throughout the day over a period of time. As such, ESM is able to generate intensive longitudinal data in a manner not possible with traditional cross-sectional research (Bolger and Laurenceau 2013), which in turn could provide a more complete accounting of changes to psychological well-being under conditions of lockdown. Indeed, researchers have called for ESM studies to better understand the impact of lockdown on mental health (Horesh and Brown 2020). To our knowledge, however, only two studies have used ESM to examine the impact of the COVID-19 pandemic so far: both studies reported that the pandemic had adverse effects on mental health (e.g., increased anxiety and symptoms of depression), but were limited to university students (Fried et al. 2020; Huckins et al. 2020).

\subsection{The Present Study}

ESM offers a useful methodological tool to examine the impact of inter-related factors on emotional well-being under conditions of lockdown in the face of the COVID-19 pandemic. Here, we present the results of an ESM study conducted in April 2020 in Austria, during which time citizens were required to maintain social distancing and were only 
allowed to leave the home under specific conditions (i.e., essential professional activities, shopping for necessities, assisting other people, and outdoor activities either alone or in the company of others from the same household). More specifically, using an ESM study design, we examined the impact that being outdoors versus indoors, the experience of loneliness, and screen-time had on a facet of emotional well-being, namely subjective happiness. Based on the review above, we hypothesised that being outdoors would be associated with higher well-being, whereas experiencing greater loneliness and greater screen-time would be associated with lower well-being. For exploratory purposes-and given that existing research has thus far treated these factors in isolation-we also examined interactive effects of all three variables on psychological well-being, as well as interactive effects with age. Finally, given the uniqueness of these data, we also report on prospective changes in well-being, loneliness, and screen-time over the study period.

\section{Method}

\subsection{Participants and Recruitment}

Participants were recruited by word-of-mouth through friends, relatives, and friends-offriends, which provided a convenience sample from the community in Austria. The study began on April 6, 2020 (i.e., about 2 weeks after the start of the nationwide 'curfew' in Austria). In total, 286 individuals began the study by completing at least three daily questionnaires (median number of completed daily questionnaires $=46$, maximum possible number $=63$ ). Only five participants did not complete the final questionnaire at the end of the study period. Participants were mainly women (56.3\%; $42.0 \%$ men; $1.7 \%$ missing) and the sample had a mean age of 31.0 years $(S D=14.5)$. In terms of relationship status, $31.5 \%$ were single, $42.0 \%$ in a relationship, $22.4 \%$ married or in a registered partnership, $1.0 \%$ were widowed, and $1.0 \%$ were divorced ( $2.1 \%$ missing).

\subsection{Measures $^{1}$}

\subsubsection{Experience Sampling Questions}

Participants were asked to complete a daily questionnaire three times a day for 21 days. The questionnaire asked participants about the number of people around them ("How many known persons are currently around you [5 m radius of sight]?", "How many unknown persons are currently around you [5 m radius of sight]?"), how lonely they felt ("How lonely do you feel right now?", visual analogue scale anchored at $0=$ not at all lonely, $100=$ very lonely), and if they were indoors or outdoors ("Are you currently inside or outside a building?": $0=$ inside, $1=$ outside). In addition, we included an item about participants' state emotional well-being [i.e., subjective happiness; (Griffiths and Stefanovski 2019)]: "How

\footnotetext{
1 Data for another project were also collected but do not form part of the present study. The additional measures were included in the daily questionnaire (an affect grid and items about sleep patterns, eating patterns, and music listening behaviours), end-of-day questionnaire (1-item satisfaction with life measure, Facebook usage, smoking behaviour), and final questionnaire (10-item satisfaction with life measure, general Facebook usage, friendship behaviour, smoking behaviour, and ESM app-specific questions).
} 
happy are you right now?" (visual analogue scale anchored at $0=$ not at all, $100=$ very). All items using visual analogue scales (VAS) were presented without a slider in a predefined position; that is, as soon as a participant touched the line of the VAS, a slider appeared that could then be moved in 1-unit increments.

\subsubsection{End-of-day Questionnaire}

At the end of each day, participants were asked how much time (in hours) they had spent in front of a screen ("How much time did you spend in front of a screen today [PC, smartphone, TV, other electronic devices with a digital screen]?").

\subsubsection{Demographic Questionnaire}

Following the installation of a self-developed ESM smartphone application (see below) and registration in the study, participants were asked to respond to a request for basic demographic details (gender, age, current relationship status).

\subsubsection{Final Questionnaire}

Following the longitudinal phase of the study, participants were asked to complete a second set of demographic items used to determine data quality (see below).

\subsection{Procedures}

Written informed consent was provided by all participants prior to their participation in the study. This was in accordance with the Declaration of Helsinki and guidelines of the local university the study took place. Approval by an ethics committee was not required because the study did not affect physical or psychological integrity, the right for privacy, or other personal rights or interests of participants, as determined by Austrian national law. No harmful procedures were used and data collection was anonymous. Participants could withdraw from the study at any time without penalty. All participants took part on voluntary basis.

This ESM study used a time-contingent sampling approach for the daily questionnaires. That means that "signals" (i.e., "beeps", "bings", or in-app reminders) were sent at random times within a pre-defined time-frame (with the exception of the end-of-the-day questionnaire). Random time-points were used instead of fixed scheduling so as to avoid responses biases due to habituation (Napa-Scollon et al. 2003). A smartphone application called ESMira (henceforth "app") was used for this project and was made freely available through the Google Play Store. The app could be downloaded anonymously and a back-end server software-located on a separate server at the first author's university information-andtechnology infrastructure - ensured communication with the app, as well as storage of data (communication was encrypted). Once the app was opened, participants were required to provide a keyword that was provided by the study authors in order to ensure that only participants who had agreed to take part could register for the study. Next, basic information about the study was provided and an informed consent form was presented. Once agreed, participants were successfully registered for the study and were given the possibility of adjusting time-frames for signals. Finally, participants were encouraged to complete as many surveys as possible without compromising their personal safety (e.g., while driving). 
Signals ("Please complete the daily questionnaire right now"; see above) were sent out three times a day for a duration of 21 days (between 7 am and $8 \mathrm{pm}$; minimum time between signals $=120 \mathrm{~min}$ ) by the app itself (i.e., in-app reminder). The signal was active for $45 \mathrm{~min}$; after that, the signal deleted itself. Additionally, a reminder was sent $15 \mathrm{~min}$ after the initial signal if no response was recorded. A similar procedure was used for the end-of-the-day questionnaire (fixed time $8 \mathrm{pm}$; no reminder, automatic deletion of signal after $60 \mathrm{~min}$ ). Participants had the opportunity to adjust the predefined time-frame for the daily questionnaire and the time-point of the end-of-the-day questionnaire at any time within the app.

The initial demographic questionnaire and the final questionnaire (see above) were also included in the smartphone app and could be completed by clicking on the name of the questionnaire on a desktop-type screen. All items across all questionnaires were presented in German. Because the smartphone app was only available for Android users, we additionally used a web-version of the smartphone app for participants $(n=75,26 \%)$ using other operating systems on their smartphones (e.g., iOS). With this web-version, questionnaires were identical in wording and display; they were only presented in a web-browser instead of the app. Because signals could not be provided through the web-version, the first author of the study sent signals as SMS text messages directly to the participants' smartphones again using a randomised time schedule.

\subsection{Statistical Analyses}

We used $R$ (R Development Core Team 2014) to conduct all statistical analyses using the lme4 package (Bates et al. 2015). Random-intercept, random-slope multi-level regression analyses were calculated to analyse the effects of environment (indoors vs. outdoors), loneliness, and screen-time on happiness. Multi-level models account for the nested design of our study with measurement occasions (level 1) nested within persons (level 2). ${ }^{2}$ All level 1 predictors were centred within participants [cwc-approach; (Curran and Bauer 2011)] and the level 2 predictor of age was grand-mean centred (Enders and Tofighi 2007; Nezlek et al. 2012).

To calculate intraclass correlation coefficient (ICC) values, we first ran a baseline model without any predictors. Next, we calculated a full random-intercept random-slopes model with all interactions included. All three-way and four-way interactions as well as all interactions with the level 2 variable of age were non-significant. Next, fixed versus random models were compared to see if random models explain additional variance compared to fixed models. Although the interaction between screen-time and being indoors versus outdoors provided a significant improvement compared to the fixed model, the model itself revealed a singular fit (i.e., random variance close to zero).

In order to avoid the dangers of overfitting and for the sake of a parsimonious model, we included only two-way interactions of level 1 variables in the final model, except for the aforementioned screen-time by indoors vs. outdoors interaction. Furthermore, we had to standardise the loneliness variable to avoid overly high eigenvalues in multi-level regression calculations. The final model is displayed below:

\footnotetext{
${ }^{2}$ Because screen-time was assessed at the end of the day and not at each measurement occasion, we also calculated a three-level model - occasions (level 1) nested within days (level 2) nested within persons (level 3). Because the model fit for the three-level model was not statistically different from the more parsimonious two-level model, we present only the results from the two-level model.
} 
Level 1 (within person): Happiness ${ }_{\mathrm{ti}}=\pi_{0 \mathrm{i}}+\pi_{1 \mathrm{i}}$ Loneliness $_{\mathrm{ti}}+\pi_{2 \mathrm{i}}$ Screen-time $_{\mathrm{ti}}+\pi_{3 \mathrm{i}}$ Location


Level 2 (between persons): $\pi_{0 \mathrm{i}}=\beta_{00}+\beta_{01}$ Age $+r_{0 \mathrm{i}}$

Level 2 (between persons): $\pi_{1 \mathrm{i}}=\beta_{10}+r_{1 \mathrm{i}} ; \pi_{2 \mathrm{i}}=\beta_{20}+r_{2 \mathrm{i}} ; \pi_{3 \mathrm{i}}=\beta_{30}+r_{3 \mathrm{i}} ; \pi_{4 \mathrm{i}}=\beta_{40}+r_{4 \mathrm{i}}$; $\pi_{5 \mathrm{i}}=\beta_{50}+r_{5 \mathrm{i}}$

We used $R_{\text {GLMM }}^{2}$ (Nakagawa et al. 2017; Nakagawa and Schielzeth 2013) as a measure of explained variance, which can be interpreted like the traditional $R^{2}$ statistic in regression analyses. $R^{2}$ marginal represents the proportion of variance explained by the fixed factors alone and $R_{\text {conditional }}^{2}$ the proportion of variance explained by both fixed and random factors. Additionally, following (Nakagawa and Schielzeth 2013), we also included AIC and BIC as information criterion indices. Following the cwc-approach of Curran and Bauer (2011), predictors were within-person centered and sample means were added as level 2 predictors in order to separate within- and between-subject variance.

\section{Results}

\subsection{Validity Check}

As a validity check, we requested demographic data at two points in the study: at the start and again in the final questionnaire. All demographic details were highly consistent across time. Participant gender was $100 \%$ consistent and, in terms of age, there were only two suspect cases (one person stated being 4 years older at the end of the study compared to the start and one person was 1 year younger than before). Relationship status was also highly consistent (contingency coefficient $=0.88, p<0.001$ ). All deviations were reasonable (e.g., single to in a relationship) and, in total, only 12 participants changed their current relationship status during the three weeks.

To analyse a possible association between motivation to participate and dropout, we calculated correlations between the compliance rate (number of assessments during the ESM part) and level 2 variables. We found no significant correlations with participant age $(r=0.10, p=0.08)$, but a significant gender-difference regarding compliance with a small-to-medium effect size (women were more compliant than men), $t=3.27, p=0.001$, $M_{\text {men }}=37.0, S D_{\text {men }}=18.9, M_{\text {women }}=44.3, S D_{\text {women }}=18.4$; Cohen's $d=0.36$ ). In terms of relationship status, no significant differences were found, $F(4,275)=1.02, p=0.400$.

\subsection{Descriptive Results}

Participants responded on average very quickly to the signal. Median response time was $2.4 \mathrm{~min}$ and only $8 \%$ of questionnaires were answered later than $20 \mathrm{~min}$ after the signal has been received (this only applies to the app users and not the Web users).

Participants were mostly indoors at the time of assessments (77.2\%; outdoors $22.8 \%$; $0.2 \%$ missing). On average, 1.09 known persons $(S D=1.29$, median $=1$, range: 0 to 15$)$ and 0.16 unknown persons $(S D=0.87$, median $=0$, range: $0-16)$ were around participants (in a $5 \mathrm{~m}$ radius of sight) during the daily assessments. These findings were not unexpected given that, during the lockdown, people were only allowed to leave the home under specific conditions (for effects over time, see Fig. 1). 


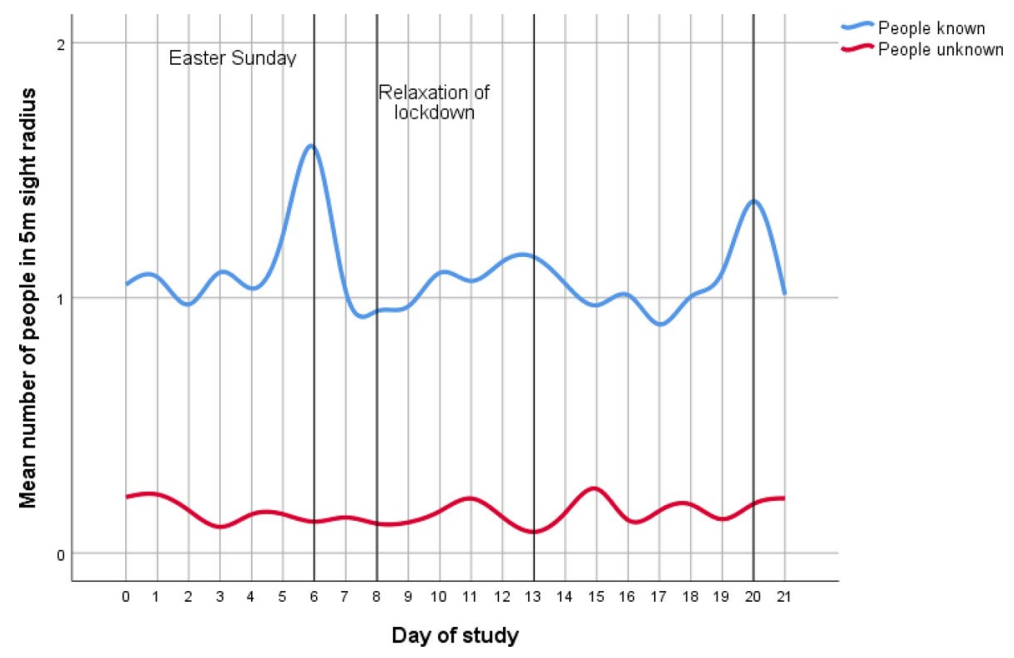

Fig. 1 Mean number of people (known vs. unknown) in $5 \mathrm{~m}$ sight radius over the study period

\subsection{Effects Over Time}

In order to analyse effects over time, random-intercept random-slopes multilevel models with the day of assessment as the predictor were calculated. Happiness improved slightly over the 21-day period (standardised $\beta=0.05,95 \% \mathrm{CI}=0.02,0.07, p<0.001$ ), loneliness fell $(\beta=$ $-0.05,95 \% \mathrm{CI}=-0.08,-0.02, p<0.001)$, and screen-time stayed constant $(\beta<0.01,95 \%$ $\mathrm{CI}=-0.03,0.04, p=0.99$ ), but all effect sizes were of a very small size (see Fig. 2). Estimates only slightly changed when taking daytime into account ( $\Delta b$ between 0.01 and 0.08$)$ significance remained the same. Using the signal number instead of the day of assessment also did not change the results substantially (happiness: standardised $\beta=0.06,95 \% \mathrm{CI}=0.03,0.09$, $p<0.001$; loneliness: $\beta=-0.06,95 \% \mathrm{CI}=-0.09,-0.03, p<0.001$; screen-time: $\beta<0.01$, $95 \% \mathrm{CI}=-0.04,0.04, p=0.99)$. Because the differences were negligible, we used the raw scores for further analyses.

\subsection{Cross-Sectional Correlations}

As expected, we found a negative correlation between happiness and loneliness (see Table 1). Interestingly, happiness was also negatively correlated with screen-time. Happiness was positively associated with the frequency of being outdoors (but not indoors) and conversely loneliness was negatively associated with the frequency of being indoors (but not outdoors). Higher loneliness was associated with higher screen-time, and greater screen-time was also associated with lower outdoor frequency (but not indoor frequency), which means that screen devices were predominantly used indoors. Finally, older participants had higher happiness, lower screen-time, and a higher outdoor frequency. 


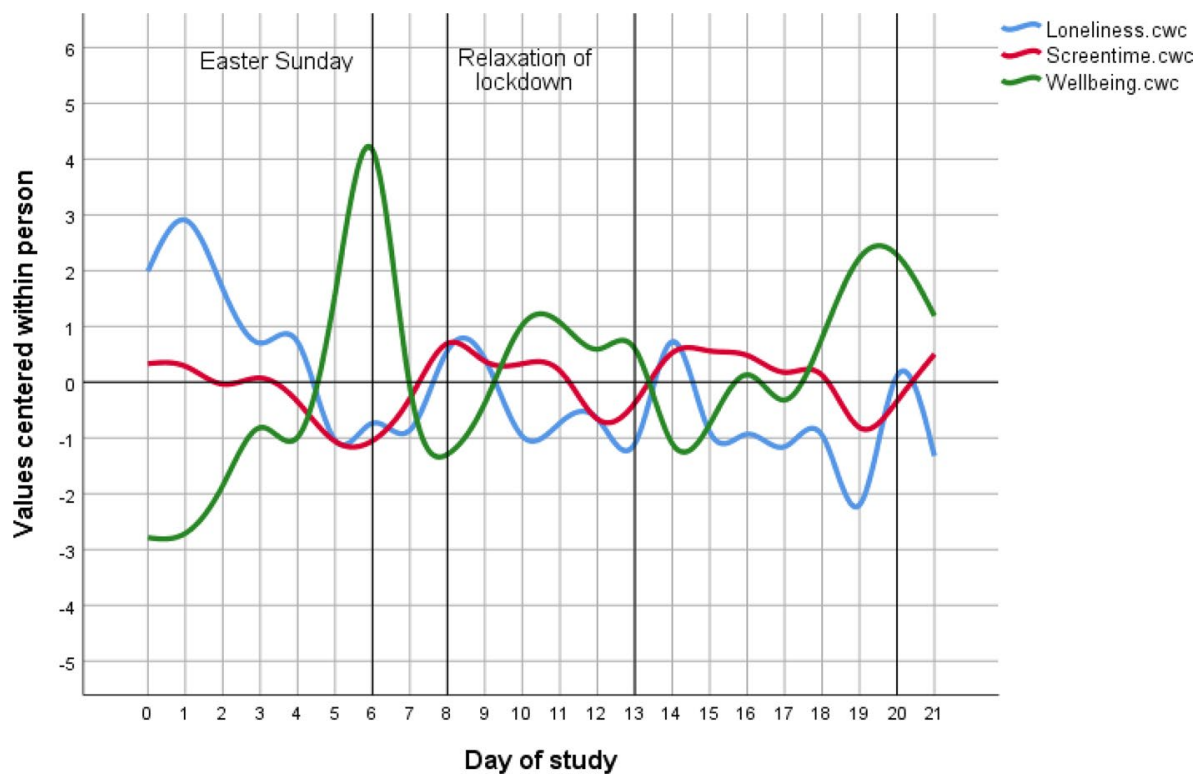

Fig. 2 Trends of the study variables over time using person-mean centered values

Table 1 Results of the personlevel analyses

\begin{tabular}{llllll}
\hline & 1 & 2 & 3 & 4 & 5 \\
\hline 1. Mean well-being & & & & & \\
2. Mean loneliness & $-.48^{* * *}$ & & & & \\
3. Mean screen-time & $-.23^{* * *}$ & $.18^{* *}$ & & & \\
4. Indoor frequency & $.11^{\mathrm{a}}$ & $-.17^{* *}$ & .08 & & \\
5. Outdoor frequency & $.24^{* * *}$ & $-.10^{\mathrm{a}}$ & $-.39 * * *$ & $.20 * *$ & \\
6. Age & $.14^{*}$ & -.08 & $-.31^{* * *}$ & -.09 & $.43^{* * *}$ \\
\hline
\end{tabular}

$N=275-286$

$* * * p<.001, * * p<.01, * p<.05,{ }^{\mathrm{a}} p<.10$

\subsection{Multi-Level (Person and Occasion) Analyses}

ICC for happiness was 55\%, which means that $55 \%$ of variance was between participants and $45 \%$ within participants. There were no substantial gender-specific differences in our key variables, so we did not include gender as a predictor in the following models (gender-specific effects: happiness: $b=-2.15$, loneliness: $b=-4.03$, screen-time: $b=-0.45$, all $p s>0.075$ ). All main effects were significant (see Table 2). Feeling lonely and having higher screen-time was associated with lower happiness, but being outdoors was associated with higher happiness. Being outdoors raised the happiness score by 3.6 points on average (0-100 VAS) and one hour more of screen-time per day reduced happiness by 0.3 points on average. An increase of one standard deviation of loneliness reduced happiness by 5.4 points on average (or put differently, 10 points more on the loneliness VAS scale reduced happiness by 3 points). In terms of interactions, only the loneliness by indoors $v s$. outdoors 
Table 2 Results of the multi-level analyses for well-being

\begin{tabular}{|c|c|c|c|c|c|c|}
\hline & \multicolumn{4}{|l|}{ Fixed } & \multicolumn{2}{|c|}{ Random } \\
\hline & Coeff. & $B[\mathrm{CI}]$ & $S E$ & $t$ & Coeff. & $S D$ \\
\hline Intercept & $\beta_{00}$ & $69.06[67.20,70.91]$ & 0.95 & $73.0 * * *$ & $r_{0 i}$ & 15.22 \\
\hline \multicolumn{7}{|l|}{ Within-person } \\
\hline Loneliness & $\beta_{10}$ & $-5.41[-6.20,-4.61]$ & 0.41 & $-13.3 * * *$ & $r_{1 i}$ & 5.16 \\
\hline Screen-time & $\beta_{20}$ & $-0.31[-0.53,-0.10]$ & 0.11 & $-2.9 * *$ & $r_{2 i}$ & 1.12 \\
\hline Indoors versus outdoors & $\beta_{30}$ & $3.58[2.76,4.40]$ & 0.42 & $8.6 * * *$ & $r_{3 i}$ & 3.41 \\
\hline Loneliness*screen-time & $\beta_{40}$ & $-0.01[-0.16,0.18]$ & 0.09 & 0.2 & $r_{4 i}$ & 0.42 \\
\hline Loneliness*Indoors vs. outdoors & $\beta_{50}$ & $1.62[0.69,2.54]$ & 0.47 & $3.4 * * *$ & $r_{5 i}$ & 3.49 \\
\hline \multicolumn{7}{|l|}{ Between-person } \\
\hline Age & $\beta_{01}$ & $0.12[-0.01,0.24]$ & 0.06 & $1.8^{\mathrm{a}}$ & & \\
\hline
\end{tabular}

$R_{\text {conditional }}^{2}=66 \%, R_{\text {marginal }}^{2}=7 \%, \mathrm{AIC}=75,979, \mathrm{BIC}=76,187$

Loneliness was standardised. Reference category for outdoors was 'indoors'.

$* p<.05, * * p<.01, * * * p<.001,{ }^{\mathrm{a}} p<.10$

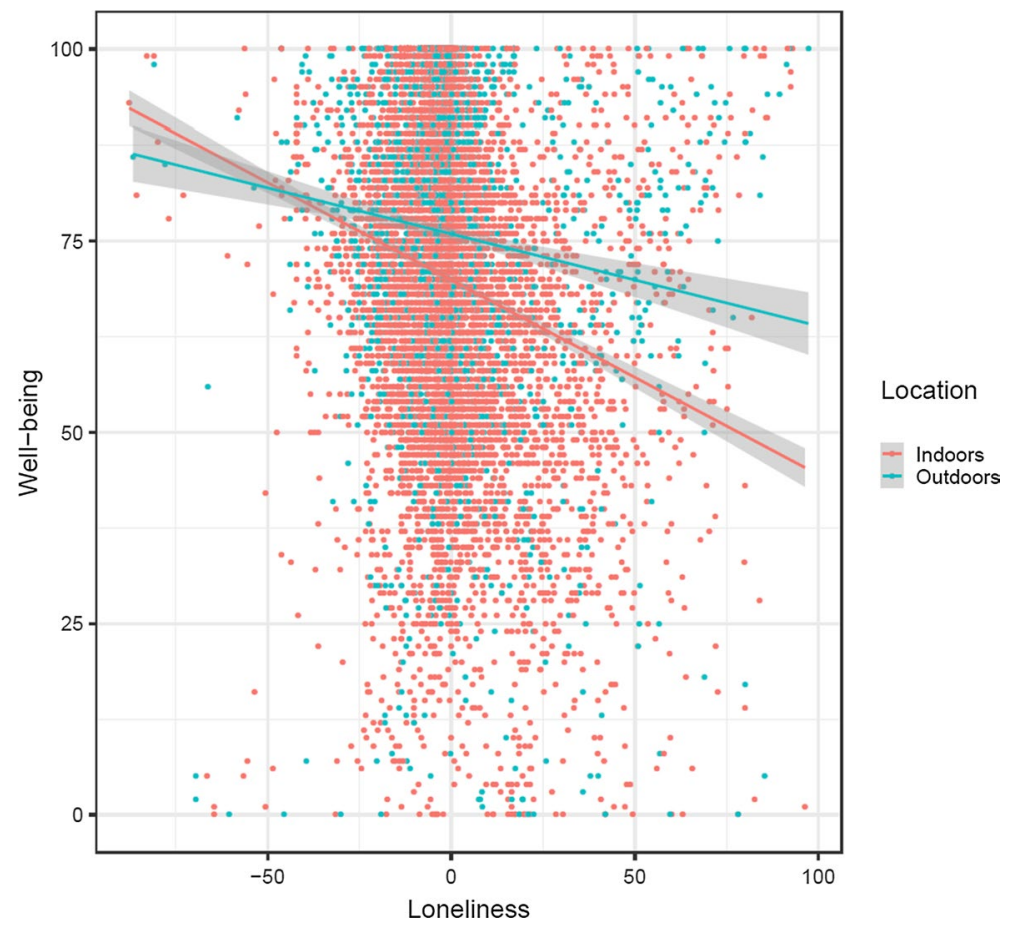

Fig. 3 The interaction between loneliness and being outdoors versus indoors on emotional well-being. Loneliness was person-mean centered 
interaction reached significance: the association between loneliness and happiness was weaker when outdoors than when indoors (see Fig. 3).

\section{Discussion}

In the present study, we used an ESM design to examine the impact of theorised antecedents on emotional well-being during the COVID-19 lockdown in Austria. In broad outline, our findings were consistent with our hypotheses: over the 21-day period of the study, being outdoors rather than indoors was associated with higher emotional well-being, whereas greater loneliness and greater screen-time were both associated with poor wellbeing, respectively. For exploratory purposes, we also examined interactive effects of being outdoors, loneliness, screen-time, and participant age on emotional well-being, but effects were generally null (with the exception of the interaction between loneliness and being outdoors). The novelty of the COVID-19 pandemic and attendant measures to reduce the transmission of the coronavirus, as well as specific study elements (e.g., conditions of restriction on outdoor activities in Austria, the time-frame of the present study) make it difficult to compare our findings with previous research and to generalise broadly. Nevertheless, based on our findings, we highlight a number of key implications.

First, we found that being outdoors was associated with higher emotional well-being, which is consistent with pre-pandemic research on the benefits of being outdoors for mental health [for reviews, see (Bowler et al. 2010; Collado et al. 2017; Frumkin et al. 2017; Hartig et al. 2014; Kondo et al. 2018; van den Bosch and Bird 2018)]. As various authors have speculated, the ability and opportunity to spend time outdoors may be especially important under conditions of lockdown and social-distancing (Burtscher et al. 2020; Samuelsson et al. 2020). Our results provide empirical evidence for these claims [see also (Lades et al. 2020)] and, although we were not able to examine whether specific outdoor environments were particularly crucial, it seems likely that being outdoors provides a myriad of opportunities for improvements to emotional well-being. These may include opportunities to physically and psychologically escape from the stressors of household confinement (e.g., lack of personal space, boredom), maintain some social relationships and improve social capital, engage in physical activity, develop a sense of connection with the world outside [for a review, see (Samuelsson et al. 2020)]. Of course, being outdoors presents its own risks in terms of limiting the spread of viruses [e.g., due to overcrowding in high-traffic zones; (Public Health England 2014)], but these risks can be managed through effective risk-minimisation strategies [for a review in relation to COVID-19, see (Freeman and Eykelbosh 2020)].

In addition, the results of the present study suggest that the experience of loneliness was associated with poorer emotional well-being. This finding is consistent both with research conducted prior to the COVID-19 pandemic indicating that loneliness is a key risk factor for poorer emotional well-being [e.g., (Cuenya et al. 2012; Wilson et al. 2007)], as well as cross-sectional data from other nations during the pandemic (2020; Losada-Baltar et al. 2020; Okruszek et al. 2020; Palgi et al. 2020). It is also consistent with our finding that participants reported very few known and unknown others in the vicinity during the daily assessments; that is, under conditions of physical and social distancing, it is not surprising that participants were generally away from others (although it should be noted that we were not able to compare these descriptive data with pre-pandemic levels), which may heighten feelings of loneliness (2020) that, in turn, contribute to poorer well-being. Beyond 
this main effect, two further findings are worth highlighting vis- $a$-vis loneliness. First, in contrast to some recent commentary [emphasising the impact of older age on loneliness; (Berg-Weger and Morley 2020; Patel and Clark-Ginsberg 2020)] and cross-sectional findings [where younger participants reported feeling lonelier; (Losada-Baltar et al. 2020; Luchetti et al. 2020)], we did not find that participant age interacted with loneliness to impact well-being. Second, and perhaps more importantly, the association between loneliness and well-being was stronger when indoors, which again highlights the benefits of being outdoors.

Our results also suggested that greater daily screen-time was associated with poorer emotional well-being, although effects were comparatively weaker than being outdoors and loneliness, respectively. Interestingly, the effect of screen-time on well-being was not indirectly influenced by loneliness or being outdoors in shaping well-being. Explaining this effect is difficult in the absence of additional data on screen usage, but it might be speculated that screen-time is a proxy for exposure to potentially stressful coverage of the COVID-19 pandemic [see (Huckins et al. 2020)], which could heighten distress [for prepandemic findings, see (Pfefferbaum et al. 2014; Vance et al. 2018)]. Another possibility is that our measure of screen-time captured both leisure and non-leisure (e.g., for work, studying) screen activities, and that a detrimental effect of the latter outweighs any positive effect of using screens for leisure (e.g., communicating with others, relaxation). It is also worth noting that, in our correlational analyses, greater screen-time was significantly associated with higher loneliness, which suggests that - under conditions of lockdownscreen-time per se may not necessarily be an effective means of buffering against feelings of isolation.

In exploratory analyses, we also examined changes in emotional well-being, loneliness, and screen-time over time. Although these findings should be interpreted with caution (e.g., we do not have comparable pre-pandemic data), our analyses indicated that, over the course of the study, there was a small improvement in emotional well-being —with a peak on Easter Monday and a smaller peak following the relaxation of lockdown conditions. Our results also showed that there was a small decrease in feelings of loneliness over the course of the study, which is similar to the ESM findings of Fried and colleagues (2020) with Dutch university students. In explaining their findings, Fried and colleagues (2020) speculated that feeling part of a broader community may have improved over time, which contributed to decreased loneliness, and that their participants may have learned over time how to develop or maintain more meaningful social relationships while under lockdown. While certainly interesting, we would nevertheless caution against strong interpretations of our findings in this regard, particularly as variations in well-being and loneliness over time were small.

\subsection{Limitations}

A strength of the present study was the recruitment of a community sample of adults. However, because of our recruitment method (i.e., convenience sampling), our sample should not be considered representative of the Austrian population, which limits the generalisability of our findings. In a similar vein, caution should be exercised when comparing the results of the present study to other ESM studies conducted during the COVID-19 pandemic (Fried et al. 2020; Huckins et al. 2020), not least because of differences in the extent and practicalities of lockdown mandates across nations and differences in the time-course of the pandemic across nations. In terms of the latter, it should be noted that our study 
began about two weeks after the start of the nationwide lockdown in Austria. Because we do not have pre-lockdown data, it is difficult to know to extent the present findings truly reflect altered behavioural and affective patterns as a result of the lockdown. That is, although our descriptive data are in line with expectations (e.g., participants reported being around very few known and unknown others at the time of assessments), ${ }^{3}$ we cannot be absolutely certain that similar effects would not have been found pre-pandemic.

Other limitations of the present study were hinted at above, but should be considered further. For example, because we measured being outdoors with a single item, we are unable to determine the specific types of outdoor environments that had the strongest effects on emotional well-being [for an example of how this might be achieved in future ESM research, see (Stieger et al. 2020)] or whether fine-grained environmental conditions affected well-being [e.g., weather, altitude; for an example, see (Stieger and Reips 2019)]. Another limitation of our measure of being outdoors was that we did not measure the type of activity that was conducted when outdoors. This is important because it is possible that being outdoors is confounded with being physical active. Indeed, emerging research suggests that Austrians were less physically active during the lockdown (Schnitzer et al. 2020) and that being physically active during the pandemic is associated with more positive psychological well-being (Płomecka et al. 2020). In particular, we cannot rule out the possibility that participants were more physically active while outdoors and/or more sedentary while indoors, although we also have no reason to believe that merely being physically active should dramatically alter the nature of our findings.

Likewise, because screen-time was measured using a single item, we are unable to explicate whether specific elements of screen-time are associated with more negative emotional well-being. That is, screen-time is likely to encompass many different forms, including both work- and leisure-related screen-time, and modalities (e.g., smartphone, television, personal computer, and so on). Different modalities of screen-time may also be related to different uses, such as relaxation, reading news (including COVID-19-related news), school or university lessons, and interacting with others. Although our method of assessing screen-time is similar to other research conducted during the COVID-19 pandemic [e.g., (Xiang et al. 2020)], the use of a single-item measure of screen-time focused on duration of use limits the conclusions that can be drawn on the basis of our results. Using multi-item measures [e.g., (Maras et al. 2015)] would be beneficial in future research.

Finally, our study was focused on a single facet of emotional well-being, namely state subjective happiness. However, this represents only a singular aspect of subjective wellbeing that is focused on the experience of positive emotions [for a review, see (Keyes et al. 2002)]. While this focus is in and of itself important, it also misses other important aspects of subjective well-being, such as the experience of eudaimonic well-being. The latter includes facets relating to psychological well-being [i.e., the challenges that individuals face as they strive to realise their unique talents; (Ryff 1989; Ryff and Keyes 1995)] and social well-being [i.e., the degree to which individuals are functioning well in the social realm; (Keyes 1998)]. As such, future research could build on the present work by

\footnotetext{
3 An almost identical ESM study was conducted in 2019 and beginning at exactly the same time-point; that is, one week before Easter $(N=86 ; 3$ weeks, daily and end-of-the day questionnaire). In this study, we asked in the daily questionnaire how many people are around you in a $5 \mathrm{~m}$ distance of sight (i.e., did not separate known and unknown people). In this study we found a mean number of people around participants of 1.81 $(S D=3.14$, median $=1$, range $0-20)$, which is significantly larger compared to the mean overall number of people in the present study $\left(t=8.69, d f_{\text {adjusted }}=2945, p<.001 ; d=0.28\right)$.
} 
incorporating assessing of emotional, psychological, and social facets of well-being [e.g., (Keyes et al. 2008)]. Doing so is likely to provide a more holistic index of the degree to which an individual is flourishing in life (Keyes 2002) and would represent a fuller account of experiences of positive mental health during pandemics.

\section{Conclusion}

The issues above notwithstanding, the present results are important because, firstly, they point to two important factors-namely the experience of loneliness and greater screentime-that may be associated with poorer emotional well-being under conditions of lockdown. Secondly, our data show that being outdoors was associated with higher emotional well-being and also mitigated some of the deleterious effects of loneliness. These findings, particularly the indication that being outdoors is important in terms of well-being, may have important practical and health policy implications. Given that the COVID-19 pandemic is likely to involve multiple waves that may require new social distancing mandates, public health policies that effectively utilise outdoor spaces as part of systemic decisionmaking may bring benefits in terms of population well-being. Of course, the effectiveness of outdoor spaces at promoting well-being will depend on how well they are integrated with other prevention policies, such as those aimed at reducing the experience of loneliness and minimising screen-time.

Acknowledgement We thank Balthasar Aboal, Sandra Aschauer, Sophie Biebl, Silvana Breuer, Michael Buchecker, Giulia Danilin, Sarah Edtmayer, Hannah Marion Graf, Franziska Christina Jedlicka, Sara Elea Jöchlinger, Sophie Kellerberger, Raphaela Komolka, Sara Maria Migdal, Martina Maria Rechl, Sophie Reiner, Stella Riegler, Sabrina Schindele, Tamara Schmid, Hannah Sertic, Maximilian Wagner, Julia Jasmin Winkler, Sarah Wittmann, and Nicole Xynos for their support with data collection.

Author's Contribution SS (Conceptualization; Formal analysis; Investigation; Methodology; Project Administration; Resources; Software; Supervision; Visualization; Writing—original draft; Writing-review and editing). DL (Conceptualization; Methodology; Software). VS (Conceptualization; Investigation; Writingoriginal draft; Writing—-review \& editing).

Funding Not applicable.

Data Availability All data, materials, and analysis scripts can be found at https://osf.io/tbv8g/.

\section{Compliance with Ethical Standards}

Conflict of interest All authors declare no conflict of interest.

\section{References}

Banerjee, D., \& Rai, M. (2020). Social isolation in Covid-10: The impact of loneliness. International Journal of Social Psychiatry, 66(6), 525-527. https://doi.org/10.1177/0020764020922269.

Bates, D., Mächler, M., Bolker, B., \& Walker, S. (2015). Fitting linear mixed-effects models using lme4. Journal of Statistical Software, 67, 1-48. https://doi.org/10.18637/jss.v067.io1.

Berg-Weger, M., \& Morley, J. E. (2020). Loneliness and social isolation in older adults during the Covid-19 pandemic: Implications for gerontological social work. Journal of Nutrition, Health, and Aging, 24, 456-458. https://doi.org/10.1007/s12603-020-1366-8.

Bolger, N., \& Laurenceau, J.-P. (2013). Intensive longitudinal methods: An introduction to diary and experience sampling research. New York: Guilford. 
Bowler, D. E., Buyung-Ali, L. M., Knight, T. M., \& Pullin, A. S. (2010). A systematic review of the evidence for the added benefits to health of exposure to natural environments. BMC Public Health, 10, 456. https://doi.org/10.1186/1471-2458-10-456.

Brooks, S. K., Webster, R. K., Smith, L. E., Woodland, L., Wessely, S., Greenberg, N., \& Rubin, G. J. (2020). The psychological impact of quarantine and how to reduce it: Rapid review of the evidence. Lancet, 395(10227), 912-920. https://doi.org/10.1016/S0140-6736(20)30460-8.

Burtscher, J., Burtscher, M., \& Miller, G. P. (2020). (Indoor) isolation, stress and physical inactivity: Vicious circles accelerated by COVID-19? Scandinavian Journal of Medicine and Science in Sports, 30(8), 1544-1555. https://doi.org/10.1111/sms.13706.

Collado, S., Staats, H., Corraliza, J. A., \& Hartig, T. (2017). Restorative environments and health. In O. Navarro, G. Fleury-Bahi, \& E. Pol (Eds.), Handbook of environmental psychology and quality of life research (pp. 127-148). Dordrecht: Springer. https://doi.org/10.1007/978-3-319-31416-7_7.

Colley, R. C., Bushnik, T., \& Langlois, K. (2020). Exercise and screen time during the COVID-19 pandemic. Health Reports, 31(6), 3-11. https://doi.org/10.25138/82-003-x2020006000001-eng.

Cuenya, L., Fosacheca, S., Mustaca, A., \& Kamenetzky, G. (2012). Effects of isolation in adulthood on frustration and anxiety. Behavioural Processes, 90(2), 155-160. https://doi.org/10.1016/j.bepro c.2012.01.003.

Curran, P. J., \& Bauer, D. J. (2011). The disaggregation of within-person and between-person effects in longitudinal models of change. Annual Review of Psychology, 62, 583-619. https://doi.org/10.1146/annur ev.psych.093008.100356.

Ellison, W. D., Trahan, A. C., Pinzon, J. C., Gillespie, M. E., Simmons, L. M., \& King, K. Y. (2020). For whom, and for what, is experience sampling more accurate than retrospective report? Personality and Individual Differences, 163, 110071. https://doi.org/10.1016/j.paid.2020.110071.

Elmer, T., Mepham, K., \& Stadfeld, C. (2020). Students under lockdown: Assessing change in students' social networks and mental health during the COVID-19 crisis. PsyArXiv. https://doi.org/10.31234/ osf.io/ua6tq

Enders, C. K., \& Tofighi, D. (2007). Centering predictor variables in cross-sectional multilevel models: A new look at an old issue. Psychological Methods, 12(2), 121-138. https://doi. org/10.1037/1082-989X.12.2.121.

Fiorilo, A., \& Gorwood, P. (2020). The consequences of the COVID-19 pandemic on mental health and implications for clinical practice. European Psychiatry, 63(1), e32. https://doi.org/10.1192/j.eurps y.2020.35.

Freeman, S., \& Eykelbosh, A. (2020). COVID-19 and outdoor safety: Considerations for use of outdoor recreational spaces. National Collaborating Centre for Environmental Health.

Fried, E. I., Papanikolaou, F., \& Epskamp, S. (2020, April 24). Mental health and social contact during the COVID-19 pandemic: An ecological momentary assessment study. PsyArXiv. https://doi.org/10.31234 /osf.io/36xkp

Frumkin, H., Bratman, G. N., Breslow, S. J., Cochran, B., Kahn, P. H., Jr., Lawler, J. J., et al. (2017). Nature contact and human health: A research agenda. Environmental Health Perspectives, 125(7), 075001. https://doi.org/10.1289/EHP1663.

Galea, S., Merchant, R. M., \& Lurie, N. (2020). The mental health consequences of COVID-19 and physical distancing: The need for prevention and early intervention. JAMA Internal Medicine, 180(6), 817-818. https://doi.org/10.1001/jamainternmed.2020.1562.

Gao, J., Zheng, P., Jia, Y., Chen, H., Mao, Y., Chen, S., et al. (2020). Mental health problems and social media exposure during COVID-19 outbreak. PLoS ONE, 15(4), e0231924. https://doi.org/10.1371/ journal.pone.0231924.

Google. (2020, May 6). Community mobility report: Austria. Google. https://www.gstatic.com/covid19/ mobility/2020-05-02_AT_Mobility_Report_en.pdf

Griffiths, S., \& Stefanovski, A. (2019). Thinspiration and fitspiration in everyday life: An experience sampling study. Body Image, 30, 135-144. https://doi.org/10.1016/j.bodyim.2019.07.002.

Hamilton, J., Nesi, J., \& Choukas-Bradley, S. (2020, April 20). Teens and social media during the COVID19 pandemic: Staying socially connected while physically distant. PsyArXiv. https://doi.org/10.31234 /osf.io/5stx 4

Hartig, T., Mitchell, R., de Vries, S., \& Frumkin, H. (2014). Nature and health. Annual Review of Public Health, 35, 207-228. https://doi.org/10.1146/annurev-publhealth-032013-182443.

Hawryluck, L., Gold, W. L., Robinson, S., Pogorski, S., Galea, S., \& Styra, R. (2004). SARS control and psychological effects of quarantine, Toronto, Canada. Emerging Infectious Diseases, 10(7), 12061212. https://doi.org/10.3201/eid1007.030703.

Horesh, D., \& Brown, A. D. (2020). Traumatic stress in the age of COVID-19: A call to close critical gaps and adapt to new realities. Psychological Trauma, 12(4), 331-335. https://doi.org/10.1037/tra0000592. 
Huang, C. (2017). Time spent on social network sites and psychological well-being: A meta-analysis. Cyberpsychology, Behavior and Social Networking, 20, 346-354. https://doi.org/10.1089/cyber .2016.0758.

Huckins, J., da Silva, A., Wang, W., Hedlund, E. L., Rogers, C., Nepal, S., Wu, J., Obuchi, M., Murphy, E. I., Meyer, M., Wagner, D., Holtzheimer, P. E., \& Campbell, A. (2020, May 4). Mental health and behaviour during the early phases of the COVID-19 pandemic: A longitudinal mobile smartphone and ecological momentary assessment study in college students. PsyArXiv. https://doi.org/10.31234/osf. io/4enzm

Keyes, C. L. M. (1998). Social well-being. Social Psychology Quarterly, 61(2), 121-140.

Keyes, C. L. M. (2002). The mental health continuum: From languishing to flourishing in life. Journal of Health and Social Behavior, 43(2), 207-222.

Keyes, C. L. M., Shmotkin, D., \& Ryff, C. D. (2002). Optimizing well-being: The empirical encounter of two traditions. Journal of Personality and Social Psychology, 82(6), 1007-1022. https://doi. org/10.1037/0022-3514.82.6.1007.

Keyes, C. L. M., Wissing, M., Potgieter, J. P., Temane, M., Kruger, A., \& van Rooy, S. (2008). Evaluation of the mental health continuum short form (MHC-SF) in setswana speaking South Africans. Clinical Psychology and Psychotherapy, 15(3), 181-192. https://doi.org/10.1002/cpp.572.

Kondo, M. C., Jacoby, S. F., \& South, E. C. (2018). Does spending time outdoors reduce stress? A review of real-time stress response to outdoor environments. Health and Place, 51, 136-150. https://doi. org/10.1016/j.healthplace.2018.03.001.

Lades, L., Laffan, K., Daly, M., \& Delaney, L. (2020). Daily emotional well-being during the COVID-19 pandemic. PsyArXiv. https://doi.org/10.31234/osf.io/pg6bw

Losada-Baltar, A., Jiménez-Gonzalo, L., Gallego-Alberto, L., del Sequeros Pedroso-Chaparro, M., Fernandes-Pires, J., \& Márquez-González, M. (2020). We are staying at home: Association of self-perceptions of aging, personal and family resources, and loneliness with psychological distress during the lockdown period of COVID-19. Journals of Gerontology Series B. https://doi.org/10.1093/geron b/gbaa048.

Luchetti, M., Lee, J. H., Aschwanden, D., Sesker, A., Strickhouser, J. E., Terracciano, A., \& Sutin, A. R. (2020). The trajectory of loneliness in response to COVID-19. American Psychologist, 75(7), 897908. https://doi.org/10.1037/amp0000690.

Maras, D., Flament, M. F., Murray, M., Buchholz, A., Henderson, K. A., Obeid, N., \& Goldfield, G. S. (2015). Screen time is associated with depression and anxiety in Canadian youth. Preventive Medicine, 73, 133-138. https://doi.org/10.1016/j.ypmed.2015.01.029.

Mehl, M. R., \& Conner, T. S. (Eds.). (2012). Handbook of research methods for studying daily life. New York: Guilford.

Ministry of Social Affairs. (2020). Coronavirus: Aktuelle Informationen [Coronavirus: Current information]. Ministry of Social Affairs. https://www.sozialministerium.at/Informationen-zum-Coronavirus/ Neuartiges-Coronavirus-(2019-nCov).html

Nakagawa, S., Johnson, P. C. D., \& Schielzeth, H. (2017). The coefficient of determination $R^{2}$ and intraclass correlation coefficient from generalized linear mixed-effects models revisited and expanded. Journal of the Royal Society: Interface, 14(134), 1-11. https://doi.org/10.1098/rsif.2017.0213.

Nakagawa, S., \& Schielzeth, H. (2013). A general and simple method for obtaining $R^{2}$ from generalized linear mixed-effects models. Methods in Ecology and Evolution, 4, 133-142. https://doi.org/10.1111/ j.2041-210x.2012.00261.x.

Napa-Scollon, C., Kim-Prieto, C., \& Diener, E. (2003). Experience sampling: Promises and pitfalls, strengths and weaknesses. Journal of Happiness Studies, 4, 5-34. https://doi.org/10.1023/A:10236 05205115 .

Newby, J., O’Moore, K., Tang, S., Christensen, H., \& Faasse, K. (2020). Acute mental health responses during the COVID-19 pandemic in Australia. PLOS ONE, 15(7), e0236562. https://doi.org/10.1371/journ al.pone.0236562.

Nezlek, J. B. (2012). Multilevel modeling analyses of diary-style data. In M. R. Mehl \& T. S. Conner (Eds.), Handbook of research methods for studying daily life (pp. 357-383). New York: Guilford.

Odgers, C. L., \& Jensen, M. R. (2020). Adolescent mental health in the digital age: Facts, fears, and future directions. Journal of Child and Adolescent Psychiatry, 61, 336-348. https://doi.org/10.1111/ jcpp. 13190.

Okruszek, Ł., Aniszweska-Stańzcuk, A., Piejka, A., Wiśniewska, M., Żurek, K. (2020). Safe but lonely? Loneliness, mental health symptoms and COVID-19. PsyArXiv. https://doi.org/10.31234/osf.io/9njps

Palgi, Y., Shrira, A., Ring, L., Bodner, E., Avidor, S., Bergman, Y., et al. (2020). The loneliness pandemic: Loneliness and other concomitants of depression, anxiety, and their comorbidity during the COVID19 outbreak. Journal of Affective Disorders, 275, 109-111. https://doi.org/10.1017/j.jad.2020.06.036. 
Pancani, L., Marinucci, M., Aureli, N., \& Riva, P. (2020). Forced social isolation and mental health: A study on 1006 Italians under COVID-19 lockdown. PsyArXiv. https://doi.org/10.31234/osf.io/uacfj

Patel, S. S., \& Clark-Ginsberg, A. (2020). Incorporating issues of elderly loneliness into the COVID-19 public health response. Disaster Medicine and Public Health Preparedness, 14(3), e13-e14. https:// doi.org/10.1017/dmp.2020.145.

Pfefferbaum, B., Newman, E., Nelson, S. D., Nitiéma, P., Pfefferbaum, R. L., \& Rahman, A. (2014). Disaster media coverage and psychological outcomes: Descriptive findings in the extant research. Current Psychiatry Reports, 16, 264. https://doi.org/10.1007/s11920-014-0464-x.

Pietrobelli, A., Pecoraro, L., Ferruzzi, A., Heo, M., Faith, M., Zoller, T., et al. (2020). Effects of COVID-19 lockdown on lifestyles behaviors in children with obesity living in Verona, Italy: A longitudinal study. Obesity, 28(8), 1382-1385. https://doi.org/10.1002/oby.22861.

Płomecka, M. B., Gobbi, S., Neckels, R., Radziński, P., Skórko, B., Lazzeri, S., et al. (2020). Mental health impact of COVID-19: A global study of risk and resilience factors. MedRxiv. https://doi. org/10.1101/2020.05.05.20092023.

Public Health England. (2014). Impact of mass gatherings on an influenza pandemic: Scientific evidence base review. Department of Health.

Qin, F., Song, Y., Nassis, G. P., Zhao, L., Cui, S., Lai, L., et al. (2020). Prevalence of insufficient physical activity, sedentary screen time and emotional well-being during the early days of the 2019 novel coronavirus (COVID-19) outbreak in China: A national cross-sectional study. Lancet. https://doi. org/10.2139/ssrn.3566176.

Qiu, J., Shen, B., Zhao, M., Wang, Z., Xie, B., \& Zu, Y. (2020). A nationwide survey of psychological distress among Chinese people in the COVID-19 epidemic: Implications and policy recommendations. General Psychiatry, 33(2), e100213. https://doi.org/10.1136/gpsych-2020-100213.

$R$ Development Core Team. (2014). R: A language and environment for statistical computing. $R$ Foundation for Statistical Computing.

Rice W, Meyer C, Lawhon B, Taff BD, Mateer T, Reigner N, Newman P (2020). The COVID19 pandemic is changing the way people recreate outdoors: Preliminary report on a national survey of outdoor enthusiasts amid the COVID19 pandemic. SocArXiv. https://doi.org/10.31235/osf.io/prnz9

Rousseau, S., \& Deschacht, N. (2020). Public awareness of nature and the environment during the COVID19 crisis. Environmental and Resource Economics, 76, 1149-1159. https://doi.org/10.1007/s1064 0-020-00445-w.

Russell, D., Cutrona, C. E., Rose, J., \& Yurko, K. (1984). Social and emotional loneliness: An examination of Weiss's typology of loneliness. Journal of Personality and Social Psychology, 46(6), 1313-1321. https://doi.org/10.1037/0022-3514.46.6.1313.

Ryff, C. D. (1989). Happiness is everything, or is it? Explorations on the meaning of psychological well-being. Journal of Personality and Social Psychology, 57(6), 1069-1081. https://doi. org/10.1037/0022-3514.57.6.1069.

Ryff, C. D., \& Keyes, C. L. M. (1995). The structure of psychological well-being revisited. Journal of Personality and Social Psychology, 69(4), 719-727. https://doi.org/10.1037/0022-3514.69.4.719.

Samuelsson, K., Barthel, S., Colding, J., Macassa, G., \& Giusti, M. (2020). Urban nature as a source of resilience during social distancing amidst the coronavirus pandemic. OSF Preprints. https://doi. org/10.31219/osf.io/3wx5a.

Schnitzer, M., Schöttl, S. E., Kopp, M., \& Barth, M. (2020). COVID-19 stay-at-home order in Tyrol, Austria: Sports and exercise behaviour in change? Public Health, 185, 218-220. https://doi.org/10.1016/j. puhe.2020.06.042.

Stickley, A., \& Koyanagi, A. (2016). Loneliness, common mental disorders and suicidal behavior: Findings from a general population survey. Journal of Affective Disorders, 197, 81-87. https://doi.org/10.1016/j. jad.2016.02.054.

Stieger, S., Aichinger, I., \& Swami, V. (2020). The impact of nature exposure on body image and happiness: An experience sampling study. International Journal of Environmental Health Research. https://doi. org/10.1080/09603123.2020.1803805.

Stieger, S., \& Reips, U.-D. (2019). Well-being, smartphone sensors, and data from open-access databases: A mobile experience sampling study. Field Methods, 31(3), 277-291. https://doi.org/10.1177/15258 $22 X 18824281$.

Swami, V., Horne, G., \& Furnham, A. (2021). COVID-19-related stress and anxiety are associated with negative body image in adults from the United Kingdom. Personality and Individual Differences, 170, 110426. https://doi.org/10.1016/j.paid.2020.110426.

Tian, H., Liu, Y., Li, Y., Wu, C.-H., Chen, B., Moritz, U. G. K., et al. (2020). An investigation of transmission control measures during the first 50 days of the COVID-19 epidemic in China. Science, 368(6491), 638-642. https://doi.org/10.1126/science.abb6105. 
Torales, J., O’Higgins, M., Castaldelli-Maia, J. M., \& Ventriglio, A. (2020). The outbreak of COVID-19 coronavirus and its impact on global mental health. International Journal of Social Psychiatry, 66(4), 317-320. https://doi.org/10.1177/0020764020915212.

Tull, M. T., Edmonds, K. A., Scamaldo, K. M., Richmond, J. R., Rose, J. P., \& Gratz, K. L. (2020). Psychological outcomes associated stay-at-home orders and the perceived impact of COVID-19 on daily life. Psychiatry Research, 289, 113098. https://doi.org/10.1016/j.psychres.2020.113098.

van den Bosch, M., \& Bird, W. (Eds.). (2018). Oxford textbook of nature and public health: The role of nature in improving the health of a population. Oxford: Oxford University Press.

Vance, M. C., Kovachy, B., Dong, M., \& Bui, E. (2018). Peritraumatic distress: A review and synthesis of 15 years of research. British Journal of Health Psychology, 74(9), 1457-1494. https://doi.org/10.1002/ jclp. 22612.

Wang, C., Pan, R., Wan, X., Tan, Y., Xu, L., Ho, C. H., \& Ho, R. C. (2020). Immediate psychological responses and associated factors during the initial stage of the 2019 coronavirus disease (COVID-19) epidemic among the general population in China. International Journal of Environmental Research and Public Health, 17(5), 1729. https://doi.org/10.3390/ijerph17051729.

Wen, L. M., Kite, J., Merom, D., \& Rissel, C. (2009). Time spent playing outdoors after school and its relationship with independent mobility: A cross-sectional survey of children aged 10-12 years in Sydney, Australia. International Journal of Behavioral Nutrition and Physical Activity, 6, 15. https://doi. org/10.1186/1479-5868-6-15.

Wheaton, M. G., Abramowitz, J. S., Berman, N. C., Fabricant, L. E., \& Olatunji, B. O. (2012). Psychological predictors of anxiety in response to the H1N1 (swine flu) pandemic. Cognitive Therapy and Research, 36, 210-218. https://doi.org/10.1007/s10608-011-9353-3.

Wilson, R. S., Krueger, K. R., Arnold, S. E., Schneider, J. A., Kelly, J. F., Barnes, L. L., et al. (2007). Loneliness and risk of Alzheimer disease. Archives of General Psychiatry, 64(2), 234-240.

Xiang, M., Zhang, Z., \& Kuwahara, K. (2020). Impact of COVID-10 pandemic on children and adolescents' lifestyle behavior larger than expected. Progress in Cardiovascular Disease, 63(4), 531-532. https:// doi.org/10.1016/j.pcad.2020.04.013.

Publisher's Note Springer Nature remains neutral with regard to jurisdictional claims in published maps and institutional affiliations. 